\title{
Integrating Commercial Greenhouses in the Smart Grid with Demand Response based Control of Supplemental Lighting
}

\author{
A. Clausen, H. M. Maersk-Moeller, Jan Corfixen Soerensen, B. N. Joergensen \\ Center for Smart Energy Solutions, University of Southern Denmark, Odense, Denmark
}

K. H. Kjaer, C. O. Ottosen
Department of Food Science, Aarhus University

ABSTRACT: In Northern Europe the production of ornamental pot plants in greenhouses requires use of supplemental light, as light is a restricting climatic factor for growth from late autumn until early spring. By participating in demand response programs such as real-time pricing, growers can schedule electricity consumption in hours where electricity prices are low, thus achieving savings in their electricity expenses. In this context we present a novel software system for dynamic control of supplemental lighting in greenhouses that aims at decreasing the electricity costs and energy consumption without loss in productivity. The software uses weather forecasts and electricity prices together with a photosynthesis model to compute energy and costefficient supplemental light plans, which fulfills the productivity goal defined by the grower. Experiments with different light control strategies revealed that electricity savings about $25 \%$ was possible without noticeable reductions in plant flowering and production time.

KEYWORD: Energy Management System; Demand Response; Smart Grid; Demand Side Management; Climate control; Supplemental Light; Photosynthesis; Weather Forecast; Electricity Cost; Decision Support; Energy Saving.

\section{INTRODUCTION}

In spite of technological advances in energy efficiency of appliances, electricity consumption is generally increasing. While generation capacity itself might not be a problem, the capacity of the electrical infrastructure is of a higher concern (Palensky \& Dietrich, 2011). In this context, peak electricity consumption is of particular concern since it induces a disproportionate effect on operational costs of the grid (Barker, et al., 2012), resulting in increased electricity prices for consumers. Further, the integration of fluctuating energy sources such as windmills and solar plants in the grid, have made electricity production more unpredictable (Samad \& Kiliccote, 2012). These challenges combined render the traditional approach, in which utilities held the sole responsibility of maintaining a stable supply situation on the electricity grid, insufficient.

Initiatives such as energy efficiency and energy conservation as well as demand response (DR) have been suggested as partial solutions to this problem (Palensky \& Dietrich, 2011). Energy efficiency focuses on replacing old appliances, making structural modifications and acts as permanent initiatives to reduce electricity consumption. Energy conservation focuses on habits and thus proposes behavioral changes in order to minimize electricity consumption, e.g. by turning off lights in unused sectors, utilizing the entire volume of washing machines and dryers before running them, reducing light set points, accepting higher room temperatures etc. DR encourages consumers to react to current electricity production and demand. In DR programs consumers are expected to react to DR signals from the utility and adapt their consumption accordingly. Consumers are encouraged through the use of incentives or variable price structures. With incentive based DR, a consumer may be offered incentive payments or bill reductions when they are able to reduce energy consumption in response to events. In a variable price scheme, price signals are sent to consumers in order to enable them to place electricity consumption in periods where prices are low. This form of DR have been introduced in the Nordic countries, where a variable price structure is available for consumers with a consumption above $100,000 \mathrm{~kW}$, allowing industries to cut costs by adjusting their electricity-consumption patterns.

However, the participation in DR programs is obstructed by the complexity of the decisions needed to effectively engage in these programs (Motegi, et al., 2007) (Cappers, et al., 2012). This poses a barrier towards industries, in which electricity accounts for 
large parts of the expenses ascribed to production. A key example of this is protected cultivation of plants.

In Denmark, year-round protected cultivation of plants requires a high-energy use for supplemental light in order to maintain both high plant quality and a well-planned plant production. Light is the energy source for plant photosynthesis and growth and when light levels are low, plants are unable to take advantage of environmental factors associated with protected cultivation such as higher temperatures and higher $\mathrm{CO}_{2}$ concentrations.

A number of approaches to climate control systems based on mathematical models (Seki, et al., 2005), more complex dynamic responses (Gauthier \& Guay, 1990) and simulation models (Jones, 1998) has been developed, but often failed due to their complexity and crop specificity, while validated microclimate models linked to both transpiration and $\mathrm{CO}_{2}$ use has been more successful (Körner, 2003). A dynamic climate control system based on a model system for leaf photosynthesis resulted in the development of an energy-minimizing and daylightdependent control system called IntelliGrow for production of ornamental pot plants using dynamic management of $\mathrm{CO}_{2}$ and temperature (Hansen \& Høgh-Schmidt, 1996) (Aaslyng, et al., 2003). The basic principle of IntelliGrow is that it regulates temperature and $\mathrm{CO}_{2}$ concentration according to the actual photosynthetic photon flux density (PPFD) thus utilizing the free energy generated by the sun and allowing the setpoints of temperature and $\mathrm{CO}_{2}$ to increase considerably, compared to standard climate control under high light conditions, and, contrarily, reduce heating during low light periods thus generating a much more dynamic range of climates compared to a traditional climate management. However, whereas the implementation of the research efforts resulted in a steady decline in the use of energy for heating purposes in Denmark of up to $38 \%$ since 1996, the energy used for supplemental light have only increased during the last 10 years (Dansk Gartneri, 2011).

The Danish greenhouse industry utilized 257.7 GWh of electricity or $0.83 \%$ of the total national electricity consumption in 2012 and it is estimated that $75 \%$ of this is used on supplemental light ${ }^{1}$. The increase in energy prices has put many growers out of business since 2010, and the remaining growers need to solve the problem of reducing their energy consumption while preserving their plant-production level and quality to stay in business.

The introduction of a variable price structure in the Nordic countries renders supplemental light control strategies in greenhouses, which do not take the fluctuating price of electricity into account, very expensive. Therefore, there is a need for control

\footnotetext{
1 Sources: The Danish Energy Association and The Danish Energy Agency
}

strategies that utilize the fluctuating price pattern to optimize the cost of using supplemental light. Furthermore, the creation of such energy and costefficient light control strategies needs to consider the natural plasticity in plants to irregular light periods especially under low light intensities, as plant photosynthetic carbon gain is mainly linked to the daily light integral (DLI), whereas plant growth rate and development is a function of temperature and the interrelation between temperature, $\mathrm{CO}_{2}$ and light integration (Liu \& Heins, 2002) (Moccaldi \& Runkle, 2007) (Oh, et al., 2009). In contrast, the distribution of the light intensities during the photoperiod, and light interruptions during the dark period, compared across treatments with the same DLI have only marginal effects on plant carbon gain in different plants species (Langton, et al., 2003) (Markvart, et al., 2009) (Kjær, et al., 2011).

However, changing the light patterns may have complex effects on the photoperiodic-dependent plant responses such as leaf development, stem elongation, and flower initiation (Thomas \& VincePrue, 1996). Furthermore, differences in light patterns may interfere with the critical day length controlling flowering induction in short-day (SD) plants, but also the time to flower in long-day (LD) and day-neutral plants (Runkle, et al., 1998) (Karlsson \& Werner, 2002) (Mattson \& Erwin, 2005) (Rohwer \& Heins, 2007) (Currey \& Erwin, 2010). Therefore some plant types may be nonsuitable for production in the irregular light environments. Despite significant disturbances of circadian light-regulated processes in plants by changing light conditions (Resco, et al., 2009) (Kjær \& Ottosen, 2011), campanula plants were only marginally affected in growth and development by changing light (Kjær, et al., 2011). This suggests that the development of induced flowers in campanula depends more on the duration of light than on the distribution of light.

Realizing that parts of plant production are able to cope with irregular light environments makes protected cultivation an ideal candidate for participation in demand response programs. In order to enable effective participation of greenhouses in a variable price electricity market, we have developed a software system which allows for integration of DR strategies at the consumer side. We have exemplified this by implementing a strategy which imports electricity prices and, combined with the use of weather forecasts, computes energy and costefficient strategies for the use of supplemental light. The software interfaces with a greenhouse ECC to effectuate the supplemental light strategies in the greenhouse. A dynamic supplemental light control is novel as most research has focused on light and temperature integration using constant conditions (e.g. (Runkle, et al., 1998)). 
This interdisciplinary paper contributes with a description of DR programs in general, a description of the developed software system including a description of the planning algorithm and the implementation of a demand response strategy to account for the variable price structure, and presents the results of our experiments with the software.

We focus on the ability to engage the protected cultivation industry into a real-time pricing demand response program, without compromising production quality. We explain the decision-making process from input such as electricity prices and weather forecasts to the output in the form of supplemental light control strategies. We demonstrate the effects of implementing these control strategies on plant performance in a greenhouse and thus the ability of implementing a real-time pricing DR strategy in the context of protected cultivation.

\section{DEMAND RESPONSE}

DR programs are programs initiated by utilities to encouraged consumers to change consumption patterns with the intention of reducing or shifting loads (Han \& Piette, 2008). In order to implement DR programs, two parties are needed: The consumer and the utility. The utility may request the consumer to adjust electricity consumption to adhere to the current situation on the electricity grid. Upon receiving this request, the consumer attempts to adapt electricity consumption in a way which fulfills the requirements of the utility, while considering local management policies (Dam, et al., 2008).

Consumers may respond to DR requests in three different ways (Samad \& Kiliccote, 2012 (Motegi, et al., 2007) (Piette, et al., 2006): manually, semiautomated and automated. With manual DR the consumers have no pre-programmed plans or systems to take care of incoming signals form the utility. Thus, with this form of DR the consumer have an operator responsible for determining and executing any actions deemed to be suitable for the current supply situation. This approach however suffers from two major weaknesses. With an operator responsible for initiating initiatives for execution during a DR event, the response exposed may differ from event to event, thus making the consumer actions more opaque to the utility. Another problem is that when no responsible operator is present at the consumer site, the consumer is unable to engage in the DR event. Lastly manual DR limits the ability to participate in DR events, since the complexity in the decision making process makes finding an optimal solution difficult in many situations. In semi-automated DR a pre-programmed response exists at the consumer site. Whenever a DR signal arrives at the consumer site, a human operator may initiate an appropriate plan for execution. This means that the response from the consumer may be more reliable than in the case with manual DR. At the same time, the complexity of determining the right strategy under a given set of circumstances is handled by software. However, an operator is still involved in the process, thus inheriting the problem of manual DR, when no suitable operator is present at the consumer site. With automated DR, the decision of whether and how to engage in a DR event is fully automated. The human link is removed from the process and thus, one of the weaknesses from the semi-automated DR approach. However, with this approach often the consumer, once committed, have no, or very little, influence on the actions taken in case of a DR event often making this approach less attractive to consumers. This illustrates a trade-off between utility convenience and consumer convenience.

Many forms of DR programs exist. The programs are generally divided into two categories: incentivebased DR and time-based rates DR (Cappers, et al., 2012). Each of the categories, alongside DR programs belonging to them, is described below. Note that many abstractions describing DR programs have been proposed (e.g. (Cappers, et al., 2012)(Han \& Piette, 2008)(Hesser \& Succar, 2011)(Albadi \& El-Saadany, 2008)(Aalami, et al., 2008)) due to the fact that DR programs may be combined in various ways to create programs which accommodate specific needs. As a result, some of the models described in the literature have been left out, as they may be considered variations of the programs described below.

\subsection{Incentive-based Demand Response}

Each of the programs in the incentive-based category are shown in Figure 1. Common for programs in this category are, that consumers are paid or reimbursed by the utility if they participate (Cappers, et al., 2012).

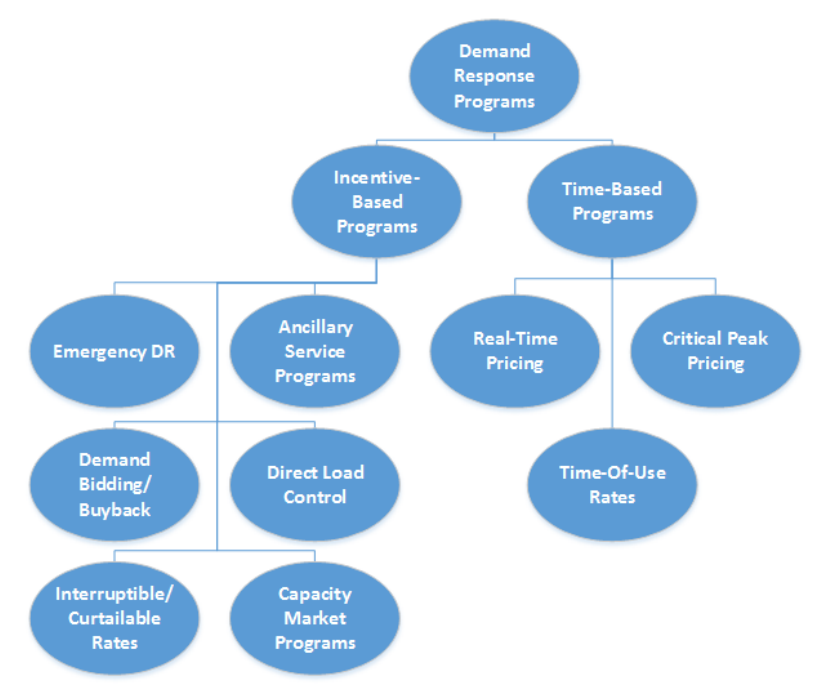

Figure 1. Demand Response Programs 


\subsubsection{Direct Load Control}

Direct Load Control (DLC) is a program, in which the utility assumes direct control over appliances at the consumer site. Given certain predefined restrictions (e.g. the amount of time a given appliance may be shutdown, "cool-down" period in which the appliance must remain turned on after an ordered shutdown, temperature set-points etc.) the utility is able to control the behavior of the appliance, thereby enabling the utility to plan consumption of the consumers in the program.

\subsubsection{Interruptible/Curtailable Rates}

Interruptible/Curtail-able Rates provides consumers with bill discounts or rate discounts, but demands from consumers enrolled in the program that they reduce or shift electricity consumption when requested by the utility. Failure to comply with the request may result in penalties depending on the terms and conditions of the specific agreement between utility and consumer.

\subsubsection{Emergency DR Programs}

In an Emergency DR Program consumers react to emergency signals sent from the utility. By being offered incentive payments, consumers are encouraged to either shut down or reduce electricity consumption during emergency conditions. In the emergency DR programs, the consumers are not penalized for not reacting to emergency signals, and thus the utility is not guaranteed any response.

\subsubsection{Capacity Market Programs}

In these programs, consumers offer a predefined part of their consumption as available load reduction. Thus, the consumer commits to reducing a certain amount of electricity consumption when requested by the utility. In this scheme consumers are usually notified day-ahead of an event and are penalized if they fail to comply with a request, as was the case with the interruptible/curtailable rates program.

\subsubsection{Demand Bidding/Buyback Programs}

This program enables consumers to bid on load reductions in the electricity wholesale market. The bid made by the consumer is accepted, if the price is lower than the market price. Whenever a bid is accepted, the consumer is obliged to reduce consumption by the specified amount. In case of failure to comply with the specification, the consumer is penalized.

\subsubsection{Ancillary Service Programs}

The ancillary service programs enable consumers with production capacity to access the wholesale markets and offer their electricity production as a regulating mechanism. In this program, consumers are paid based on the wholesale market price for the particular service they offer. Title, author and affiliation frame

\subsection{Time-based Rates Demand Response}

Unlike incentive-based DR, time-based rates programs do not offer direct payments or reimbursements to the consumers. Instead, consumers are motivated to participate by adapting their consumption to variable prices, thus replacing the traditional flat-rate price scheme on electricity. The degree to which the consumer adapts his electricity consumption to periods of low prices determines the gain obtained from these types of programs.

\subsubsection{Time-of-use Rates}

Time-of-use (TOU) rates are the simplest form of time-based rate DR. With TOU rates electricity prices vary within predefined blocks of time, e.g. peak and off-peak periods. In this program, prices reflect the average cost of electricity during the specified interval.

\subsubsection{Critical Peak Pricing}

Critical Peak Pricing (CPP) is a program in which the price of electricity is increased significantly a limited number of days or hours each year. This is done to prevent contingencies or to avoid high electricity consumption among consumers during periods of high wholesale prices.

\subsubsection{Real-time Pricing}

Real-time pricing (RTP) is the most direct form of time-based rate DR in the sense that consumers participating in this program are charged with hourly prices reflecting those of the wholesale market. In RTP consumers are informed of prices on an either day-ahead or hour-ahead basis. A form of RTP DR program is offered to consumers in the Nordic countries consuming more than $100,000 \mathrm{~kW}$, and thus this program is of particular interest to this paper.

\section{EXPERIMENTAL FRAMEWORK}

In order to provide the capability to seamlessly engage in demand response programs, we propose an application, DynaLight Desktop, which provides growers with price-optimized supplemental light plans. These light plans enable the operators at greenhouses to integrate light patterns that are optimized not only towards plant growth, but also taking into account price signals and weather forecasts. 
The overall setup of our system and its interconnections are illustrated in Figure 2. The system consists of five different entities: The greenhouse, an electricity-price SQL database server, a weather-forecast SQL database server, a commercial greenhouse environmental climate computer (ECC), and finally a desktop computer running DynaLight Desktop. In our setup the greenhouse is equipped with high-pressure sodium lamps (SON-T agro, $600 \mathrm{~W}$, Philips, Eindhoven, The Netherlands). The desktop computer is connected to the two SQL database servers over the Internet using TCP/IP, while the connections between the desktop computer, the ECC and all the way down to the equipment in the greenhouse are based on the ArcNet communication protocol.

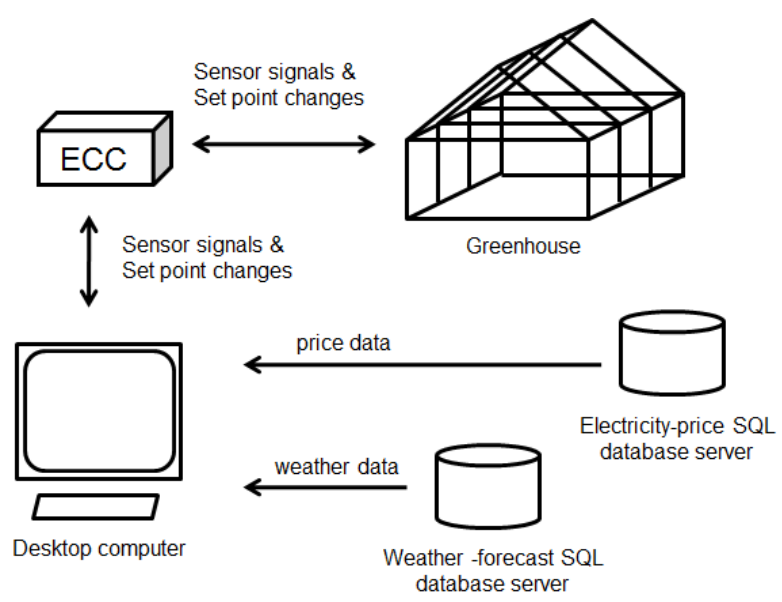

Figure 2. The principle setup and links between a greenhouse, a standard climate computer, the electricity-price SQL database server, the weather-forecast SQL database server and a PC running DynaLight Desktop.

\subsection{DynaLight Desktop}

DynaLight Desktop is the software that provides growers with price-optimized supplemental light plans. It is based on the NetBeans Rich Client Platform for development of component-based desktop applications. The NetBeans Rich Client Platform provides a framework for a modular application design that is easily extensible through its build-in plug-in architecture. The plug-in architecture have been used to create the different viewing elements of the main screen that consists of an "Overview Window" displaying a tree structure with greenhouses and compartments as shown in Figure 3 (A) "Compartment" is one of the central concepts which each represent an individually controlled area within a greenhouse complex. The properties of these compartments are configured based on their real-life counterparts. The properties consist of average indoor temperature, $\mathrm{CO}_{2}$ level, locality on the electricity grid, power consumption of lamps per squ are meter, size of compartment, glass-transmission factor, PPFD and several others. These are measured and/or supplied by the grower. The results of all analyses are shown in the "ChartDisplayer Window" (B). The ChartDisplayer Window consists of (1) the lightplan chart, where the blue line shows the resulting light plan and the red line shows whether light was forced on or off. The development in the data series for the day is shown on (2), and whether they are selected or deselected are shown below on (3). Finally, (4) shows the final results as numeric values, among others the total cost of using supplemental light and the resulting Daily Photosynthesis integral (DPI).

The tree structure, illustrated in Figure 3 (A), reflects the physical layout of greenhouses and compartments. The grower initially sets it up. The grower can create an arbitrary number of greenhouses and compartments and provide them with a name reflecting e.g. building structure, species or production stages. The compartments are all created with default properties, but in order to get the most accurate light plans and results, the grower needs to specify the properties according to the values of the physical greenhouses and compartments (e.g. glass-transmission factor). The properties can be modified and inspected by right clicking on a compartment in the "Overview Window" (Figure $3(\mathrm{~A})$ ).

The grower right-clicks on a compartment and chooses the action "Perform an analysis" to create a supplemental light plan. When a supplemental light plan is created, the grower can open the "Analysis Results" folder below the compartment to inspect the results. An open Analysis Results-folder is illustrated in the right-hand side of Figure 3 (A).

There are three different entries for each analysis performed. These are: "Chart", "Plan" and "Parameters". When the grower selects Chart, the graphical representation of the resulting light plan is displayed (Figure 3 (B)). Right-clicking on Plan gives the option to write setpoints to the ECC, which will effectuate the plan just created, effectively resembling a semi-automated demand response, as the plan is created automatically based on current prices. The last entry, Parameters, is used to create a recurring analysis with the same photosynthesis goals and parameters as the one selected, that runs automatically once a day and writes the resulting light plan to the ECC. 


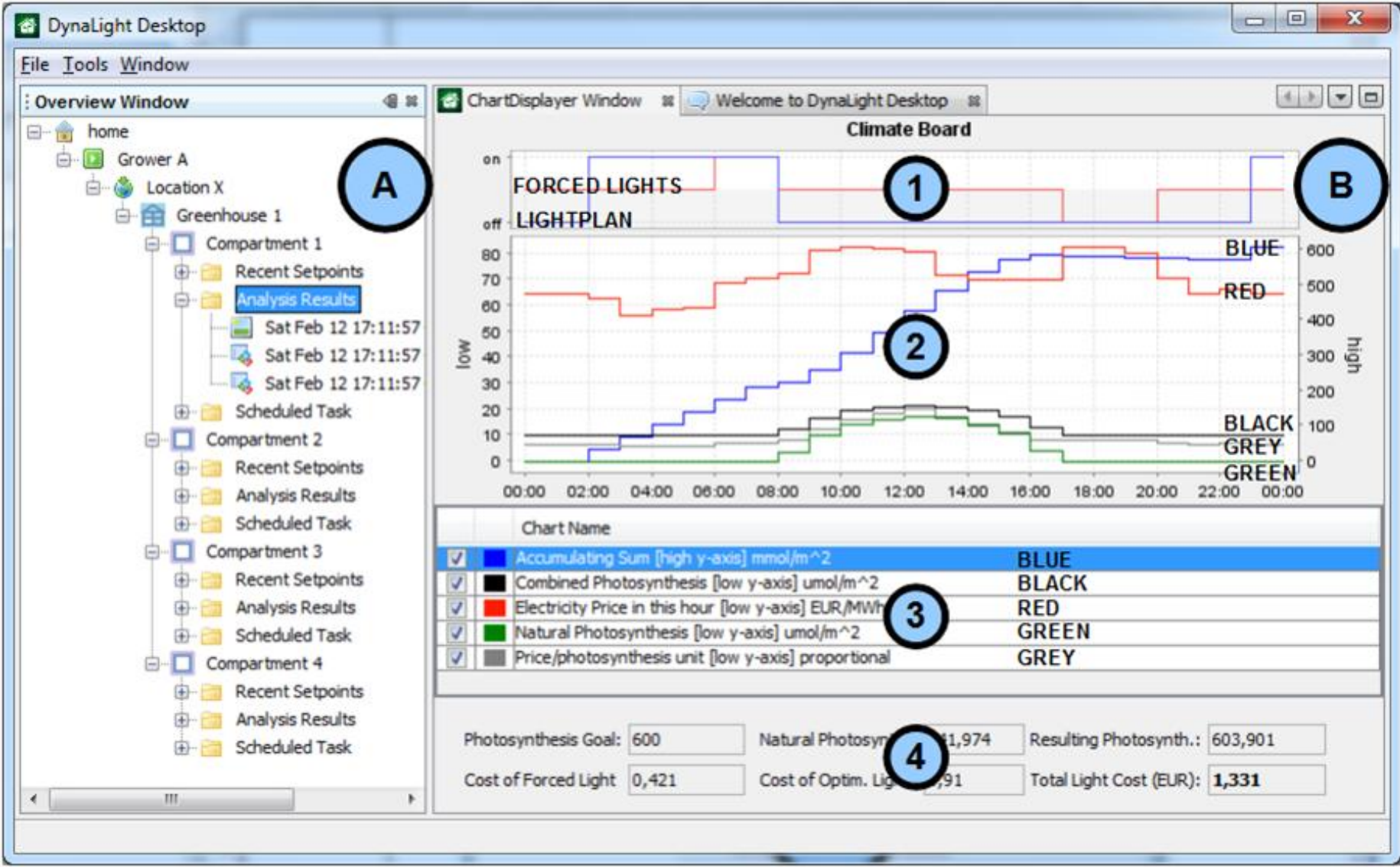

Figure 3. DynaLight Desktop Main Screen with an Overview Window (A) displaying greenhouses and compartments. The ChartDisplayer Window (B) consists of the light plan chart (1), and the data series (2), their chart legend (3), while (4) shows the final results.

This feature enables us to control the greenhouse without intervention of the grower. In DynaLight Desktop a repeating task is called a "Running Task" and when such a task has been set up, it will be shown in the folder "Scheduled Task". The last compartment folder to be described is "Recent Setpoints", which is used to inspect the latest setpoints written to the ECC.

When the grower asks for an analysis to be performed, the wizard illustrated in Figure 4 is started, in which a supplementary light plan is created. The calculations are based on the parameters provided by the grower while stepping through the wizard and the properties set for the compartment being dealt with. The grower is asked for the date being processed (1). The grower is provided with the possibility to force specific hours on/off (2). The forced hours are then outside the control of the algorithm. This can be required if the grower is using the supplemental light as working light or has specific agreements with his electricity supplier not to use electricity within certain periods of the day. The grower is asked if he only wants to do a cost analysis based on the specification provided in (2) or if the optimization algorithm should create a plan (3). The grower is asked for the photosynthesis goal and the amount of consecutive hours of darkness required by the plants (4). These hours of darkness are restitution hours required by the plants between periods of light, and vary from species to species.
The result is displayed (Figure 4 (5) and (6)), resembling the display in the Chart Displayer in Figure 3 (B). This workflow does not need to be repeated every day, as it can be made into a "Running Task" as explained previously in this section. Furthermore, the Running Task can effectuate the plan by writing it autonomously to the $\mathrm{ECC}$, and thereby transforming the analysis tool to an autonomous control system. Thus the grower does not need to monitor the process every day, and as a result the grower is able to participate in the RTP DR program in an automated fashion.

DynaLight Desktop retrieves weather forecasts and electricity-price data from the SQL databases on the two database servers. The program uses the supplemental light-planning algorithm (section 3.4) to create a light plan for the greenhouse. The supplemental light plan is translated into a list of setpoints for the ECC, which is responsible for regulating the supplemental light. The communication interface to the ECC also allows reading of its different sensors, but we do not currently utilize this feature.

\subsection{Electricity Prices}

The industrial-size growers in Denmark that consume more than $100,000 \mathrm{~kW}$ can buy electricity in a demand response fashion on the Nordic electricity spot market, called Nord Pool Spot (Nord 
Pool Spot AS, Lysaker, Norway). This market covers Norway, Finland, Sweden, Estonia and Denmark. The spot market works in the following way: Prices are predetermined for each hour of the forthcoming day's 24 hours based on supply and demand bidding, corresponding to a RTP DR program in which a low demand and a high supply will result in low prices. The price table determined for the forthcoming day is published each day at 1 pm on the website of Nord Pool Spot. The growers can utilize the electricity during the relatively cheaper hours and thus reduce costs compared to a flat-rate price agreement. Four of the five of industrial growers involved in the research project buy on the spot market for this reason, while the last uses a flat-rate price.

The electricity-price SQL database server is updated with the latest price data using an independent program running on the server itself. When new prices are published by Nord Pool Spot on http://www.nordpoolspot.com the data are transferred and stored in the database on the server.

\subsection{Weather Forecasts}

Weather forecasts were provided by the company ConWx (ConWx ApS, Frederiksberg, Denmark). The weather is forecasted four times a day and 180 hours into the future with hourly resolution. The weather forecasts are specific for the location of each grower, as the grid size of the weather forecast is 0.15 degrees longitude and latitude (equivalent to approx. $10 \mathrm{~km} \mathrm{x} 16 \mathrm{~km}$ in Denmark). ConWx provides the data by uploading them to a non-public FTP server accessible over the Internet.

The weather-forecast SQL database server works in similar fashion as the electricity-price SQL database server with a server program for updating its database when new data becomes available from ConWx. The program fetches the forecasted weather data from ConWx's FTP server four times a day for all the locations at once, does some data transformations and stores the data in the SQL database for use in DynaLight Desktop.

\subsection{Planning Algorithm}

The planning algorithm utilizes the weather database and the electricity price database to generate a supplementary light schedule. The idea behind the planning algorithm can be explained using Figure 5, which shows the dynamics of the electricity prices, the natural light, the natural photosynthesis and the photosynthesis carbon gain over a day. The series displayed is selected from authentic data for Aarslev (Denmark, Lat. $55^{\circ} \mathrm{N}$ ) for the 7th December 2010, and is an example of the general dynamics of the light distribution challenges. The chart is linear interpolated between the hourly data points and displayed in percentage according to their value range. This does not illustrate the electricity-price pattern well as it should be a square-shaped series. However we found that the linear interpolation clearly reflects the important dynamics of the problem. The forecasted natural light level is shown over 24 hours and is the controlling factor for the photosynthesis model (where for simplicity the $\mathrm{CO}_{2}$ level and temperature is kept constant). The photosynthesis caused by the natural light level is shown on Figure 5 as well. The electricity prices have a characteristic diurnal pattern with peaks in the early morning and in the late afternoon. The pattern relates to the increased demand for electricity caused by human activities, e.g. when people get ready to go to work and come home to make dinner and when industrial consumption rises in late morning. These hours are also referred to as the boilerplate hours. The lowest prices are typically occurring late in the night.

The last series is the photosynthesis gain, which shows how much photosynthesis is gained by using supplemental light. The series show that supplementary lights have the highest effect when the natural light is lowest. It can be observed from Figure 5 that hours with similar photosynthesis carbon gains may differ significantly in electricity prices.

From a planning perspective prioritizing the hours with the highest carbon gains seems a good idea if the objective is solely to select hours where the use of electricity has the largest impact on plant growth. However, this approach has the obvious flaw that the price of the particular hour is not taken into consideration. This means that very expensive hours could be prioritized over cheaper hours with almost similar photosynthesis carbon gains. The presented planning algorithm remedies this problem by taking the electricity prices into account.

We combine the weather forecast and the electricity prices to create an energy and costefficient supplemental light plan for the 24 hours of the forthcoming day. The planning algorithm is illustrated in Figure 6. The forthcoming day is split in hourly time slots, mainly because electricity prices are fixed on an hourly basis.

The first seven steps in the planning algorithm can be viewed as necessary preparation steps to enable the final creation of the light plan. A global data structure is used to pass all information and intermediate results among the different steps in the algorithm. The first step requires the grower to provide the photosynthesis goal for the forthcoming day. The second step obtains the outdoor solar irradiance for the forthcoming day from the weather forecast database with one-hour resolution. The third step con-verts the solar irradiance to light intensity inside the greenhouse. This conversion uses, amongst other parameters, the light transmission 


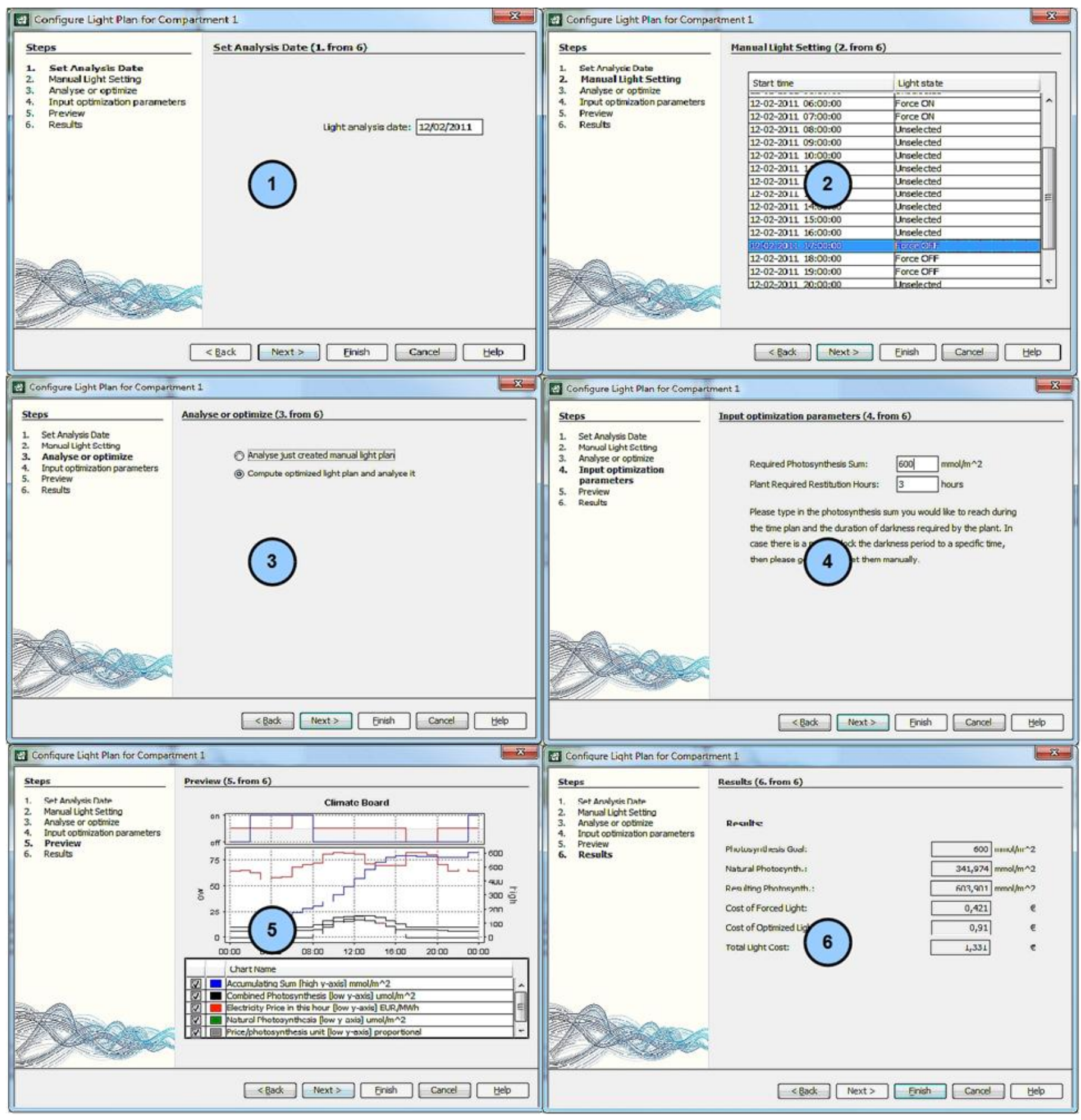

Figure 4. The DynaLight Desktop wizard flow for creating a supplemental light plan. The date of the light plan is selected in (1), and in (2) forced on/off hours are defined. In (3) it is chosen whether the cost analysis should be done only on the defined forced hours or if the optimization algorithm should be used to create the entire light plan. The photosynthesis goal and the amount of consecutive hours of darkness required by the plants are set in (4), and the result is previewed in (5) and (6).

factor of the greenhouse.

The temperature and the $\mathrm{CO}_{2}$ level, which is controlled by the ECC, together with the suninduced light on leaf level enable us to calculate the potential photosynthesis for each hour of the forthcoming day. The photosynthesis calculation utilizes the photosynthesis component of the IntelliGrow system (Aaslyng, et al., 2003). The result of this fourth step is called the natural photosynthesis gain and is stored as an intermediate result in the data structure being passed between the steps of the process.
Since we know the amount of light provided by lamps, we can combine the contribution of the supplementary and natural light to calculate the combined photosynthesis for each of the hours, as if the lamps were turned on. Afterwards we subtract the photosynthesis gain of natural light from the combined photosynthesis gain, yielding the photosynthesis gain caused exclusively by supplemental light for each of the hours in question. We calculate the photosynthesis gain this way as the photosynthesis model is non-linear (Figure 7). The result of this fifth step of the algorithm is called the supplemental photosynthesis gain. 


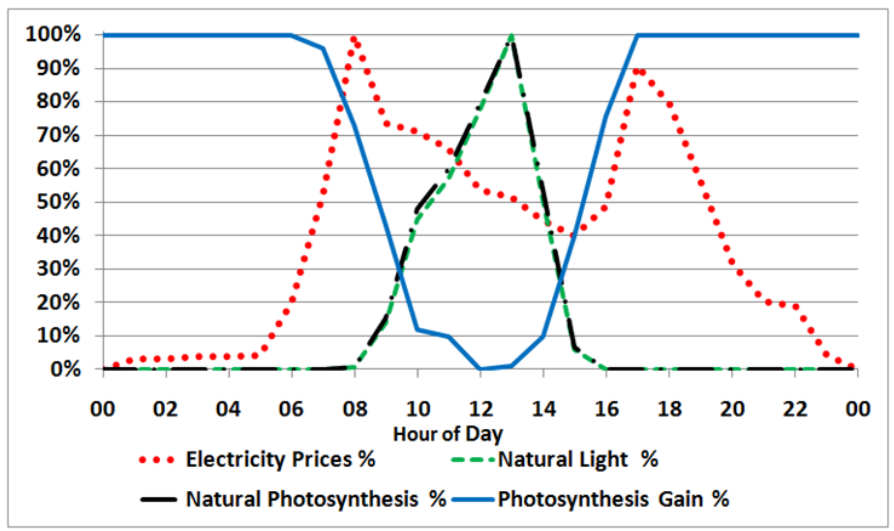

Figure 5. An example of the dynamics of price, light level, photosynthesis and gain during a day.

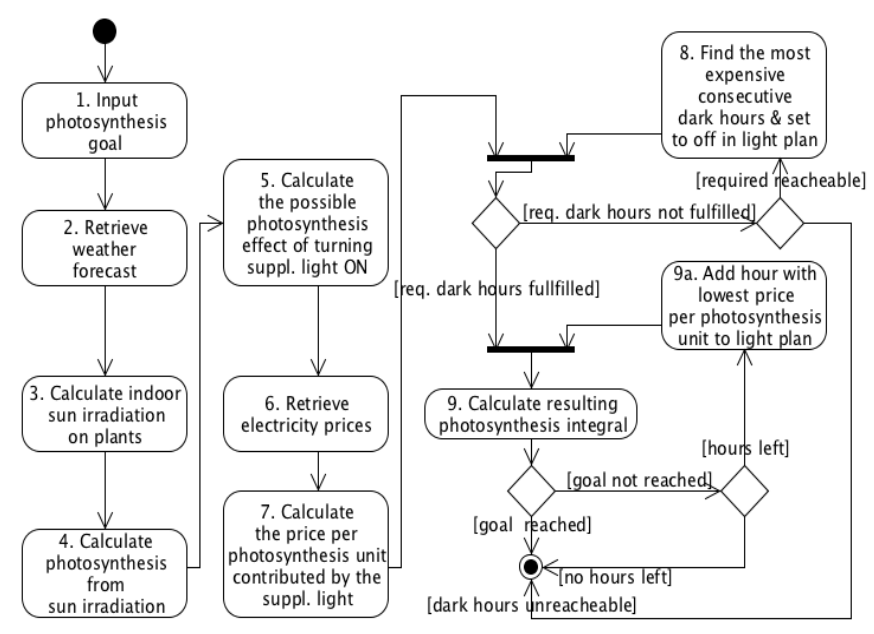

Figure 6. Unified Modeling Language (UML) Activity Diagram of the Planning Algorithm.

The hourly electricity prices for the forthcoming day are retrieved from the electricity-price database and used to calculate the total price of light per hour. This calculation depends on the total power consumption of the lamps in the greenhouse compart-ment. The prices of having the lamps turned on during the different hours are stored as intermediate results concluding the sixth step.

The seventh step uses the previously calculated supplemental photosynthesis gains and the price of light per hour to calculate the price per photosynthesis gain unit for each hour of the forthcoming day. The hourly results for price per photosynthesis gain unit are then stored for later processing. When all the initial calculations are finished the selection of hours for the resulting supplemental light plan can be made.

The conditional branching of the algorithm is based on the given need for restitution hours (dark hours) for the plants. In case there is no need for dark hours, the algorithm proceeds to step nine where the calculation of daily photosynthesis integral of the light plan is done. When plants have a need for dark hours, then the alternative route to find the most optimized sequence of dark hours is made

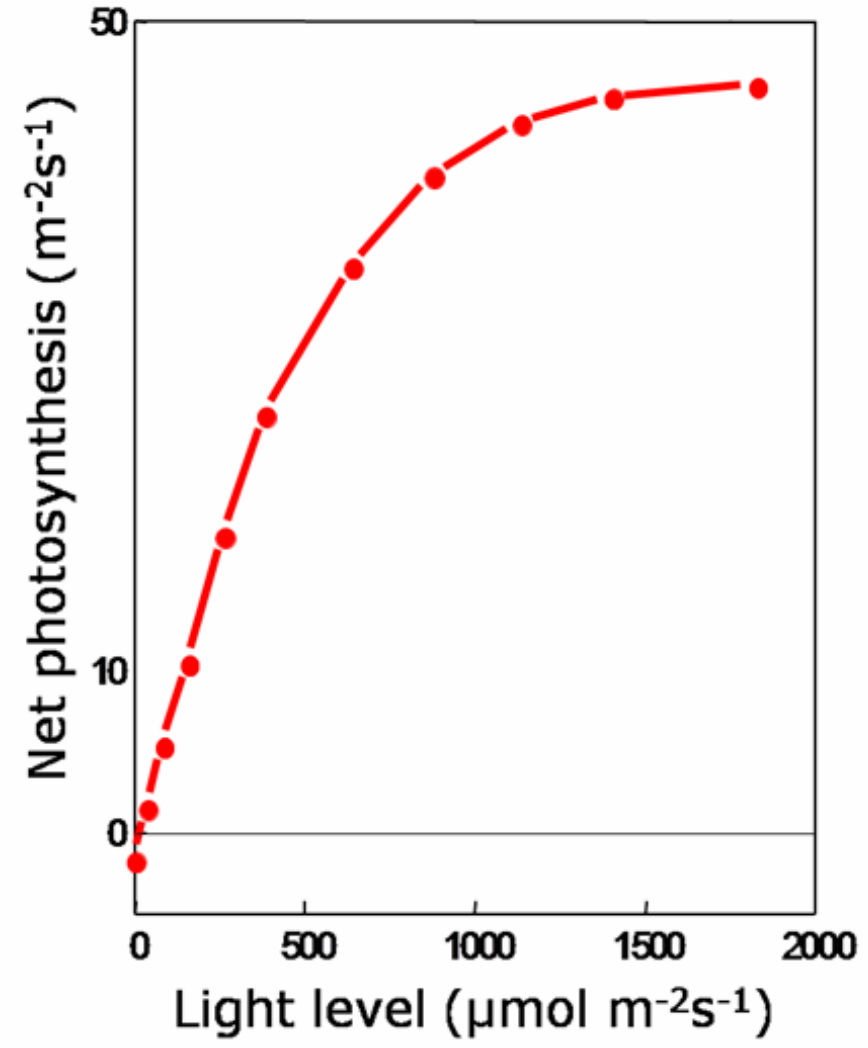

Figure 7. Simplified photosynthesis gain as function of light level

in step eight. Before the finding of optimized dark hours is done, the conditions are tested to see if it is possible to fulfill the required dark hours. In case there are not enough available consecutive dark hours, the algorithm notifies the user and terminates the analysis. This happens if the night length is shorter than the required number of dark hours to allow the user to revise the light requirements and rerun the algorithm. In case there are enough dark hours available to fulfill the requirements, then all possible placements of consecutive hours corresponding to the required number of dark hours are evaluated on price per photosynthesis unit. The sequence of dark hours that would have resulted in the highest average price per photosynthesis unit gained is selected for darkness and marked as lampoff hours in the light plan.

The ninth step of the algorithm sums the resulting photosynthesis from the light plan including the natural occurring photosynthesis. In case the sum does not fulfill the photosynthesis goal, the algorithm moves to step 9a where an additional hour of light is added to the light plan. The decision on which time slot to add to the light plan is based on the price to photosynthesis gain ratio - the hour with the lowest price per photosynthesis gain unit is selected. The algorithm sums the photosynthesis of the new plan and holds it against the growerspecified goal. If the goal is fulfilled, the algorithm returns the final light plan, if not, it moves to step 9a again. If the goal is not reached and there are no more time slots available for turning the lamps on, 
the algorithm notifies the grower and terminates. This situation may happen if there is a mismatch between the requirements of a species and the actual lamp configuration of the greenhouse. The installed lamp capacity may simply not be enough to provide the required amount of supplemental light during the darkest winter months.

\section{EXPERIMENTS}

Since 2009 DynaLight Desktop has been used to perform experiments at Aarhus University (Aarslev, Denmark). Experiments conducted in autumn 2009 and spring 2010, compared plant growth under standard climate conditions with different light treatments.

The experiments were performed in compartments each 9.9x7.6m divided into two units to allow for two treatments in each compartment with different light settings. The setpoint for $\mathrm{CO}_{2}$ was $700 \mu l * l^{-1}$ during the light periods (day or supplemental light), the night temperature was $15^{\circ} \mathrm{C}$ and the average day temperature was $18^{\circ} \mathrm{C}$. Supplemental light provided $\sim 60 \mu \mathrm{mol}^{*} \mathrm{~m}^{-2} * \mathrm{~s}^{-1}$ at table level by high-pressure sodium lamps (SON-T agro, 600W, Philips, Eindhoven, Netherlands).

During the experiments a broad range of species were tested, including campanula, chrysanthemum, roses, hibiscus, tomato and kalanchoe. However, since we focus on system concepts and energy consumption, only selected relevant plant data will be presented, and we refer to publications on chrysanthemum and campanula for a more in-depth coverage of the experiments from a plant physiological perspective (Kjær, et al., 2011) (Kjær \& Ottosen, 2011) (Kjær, et al., 2012).

During the autumn of 2009 and spring of 2010 two trials were carried out with potted roses (Rosa L., hybrids 'Mercedes', 'Escimo' and 'Pearl'). The trials included experiment 1: 1 October - 25 November 2009 (56 days) and experiment 2: 6 January - 4 March 2010 (56 days). In both experiments plants were all grown to maturity. Inside the greenhouse, light intensity (PPFD), air temperature, relative humidity $(\mathrm{RH})$ and $\mathrm{CO}_{2}$ concentrations were recorded in each treatment at bench level. Additionally, the state of supplemental light (on or off) was recorded via the ECC (LCC Completa Senmatic, Søndersø, Denmark). The PPFD was recorded at a weather station above the greenhouse, and the light-transmission factor of the greenhouse (0.5) was used to calculate the light intensity inside the greenhouse in $\mu \mathrm{mol} \mathrm{m} \mathrm{m}^{-2} \mathrm{~s}^{-1}$. The daily light integrals from supplemental light and natural PPFD were summarized. Daily light duration (DLD) was calculated as the number of hours of solar irradiation during the day plus the total number of hours that the supplemental light was turned on during the night.

The rose plants were subjected to four treatments including a long-day treatment (LD) where the natural light period was extended by seven hours of supplemental light (this treatment was comparable to the growers' specified climate conditions for a spring period) and three dynamic light treatments where the daily light period depended on the DPI setpoints. The dynamic light treatments had a varying length of night breaks of light $(\mathrm{NB})$ and included a $600 \mathrm{NB}$ treatment with a setpoint of $600 \mathrm{mmol} \mathrm{CO}_{2} \mathrm{~m}^{-2}$ leaf $d^{-1}$, a $450 \mathrm{NB}$ treatment with a setpoint of $450 \mathrm{mmol}$ $\mathrm{CO}_{2} \mathrm{~m}^{-2}$ leaf $d^{-1}$ and finally a $300 \mathrm{NB}$ treatment with setpoint of $300 \mathrm{mmol} \mathrm{CO}_{2} \mathrm{~m}^{-2}$ leaf $\mathrm{d}^{-1}$.

\subsection{Statistical analysis of plant experiments}

Statistical analysis was carried out using the Rlanguage 'stat' package, release 2.12.0 (R Foundation for Statistical Computing, 2010). The recorded climatic data from the two plant experiments were extracted from the environmental climate computer and values of means, max, min, sum and standard errors of PPF and hours of light were calculated in relation to treatment using the 'SummaryBy' work package (doBy). The effects of treatments on total means of climatic parameters and harvest data of plant dry weight (DW) and numbers of flowers were analyzed by the analysis of variance (anova). Means of the different treatments were separated by a pair wise t-test using the Bonferroni correction $(95 \%$ confidence intervals).

\section{RESULTS}

\subsection{Plant growth and light environment}

The dynamic-light-control settings resulted in highly irregular light environments with one or more light periods of different length in all three dynamic light treatments in comparison to the LD treatment, where the period of natural irradiance was extended with 7 $h$ of supplemental light from 00:00 to 07:00 in the morning as displayed in Figure 8. In the autumn experiment, this resulted in identical DLI's in the dynamic light treatments with a setpoint of 300 and $450 \mathrm{mmol}^{\mathrm{CO}} \mathrm{m}^{-2} \mathrm{leafd}^{-1}$ (DPI) and in the LD treatment with a consecutive light period of approximately $14 \mathrm{~h}$ (Table 1). However, in the dynamic light treatments the light period was divided into an average of 1.8 separate light periods per day, and the night break during the dark period was in average 5.6 hours. In spring, similar DLI's were found in the $450 \mathrm{NB}$ and the LD treatment.

In general, growth and development of the three rose cultivars were similar affected by the four treatments during the two experimental periods, and therefore, plant-growth parameters were pooled for 
the three varieties. In the autumn experiment, plantdry-matter production was increased in the $450 \mathrm{NB}$ compared to the LD treatment, whereas plant-drymatter production was decreased in $450 \mathrm{NB}$ compared to the LD treatment in spring (Table 1), However, despite these effects on dry-matter production, there were no significant differences in flower number among the LD, $450 \mathrm{NB}$ and $600 \mathrm{NB}$ treatments in both the experimental periods illustrating that the rose plants responded to the duration of light and not to the distribution of light confirming that the irregular light conditions had no effect on plant growth and development of dayneutral rose plants.

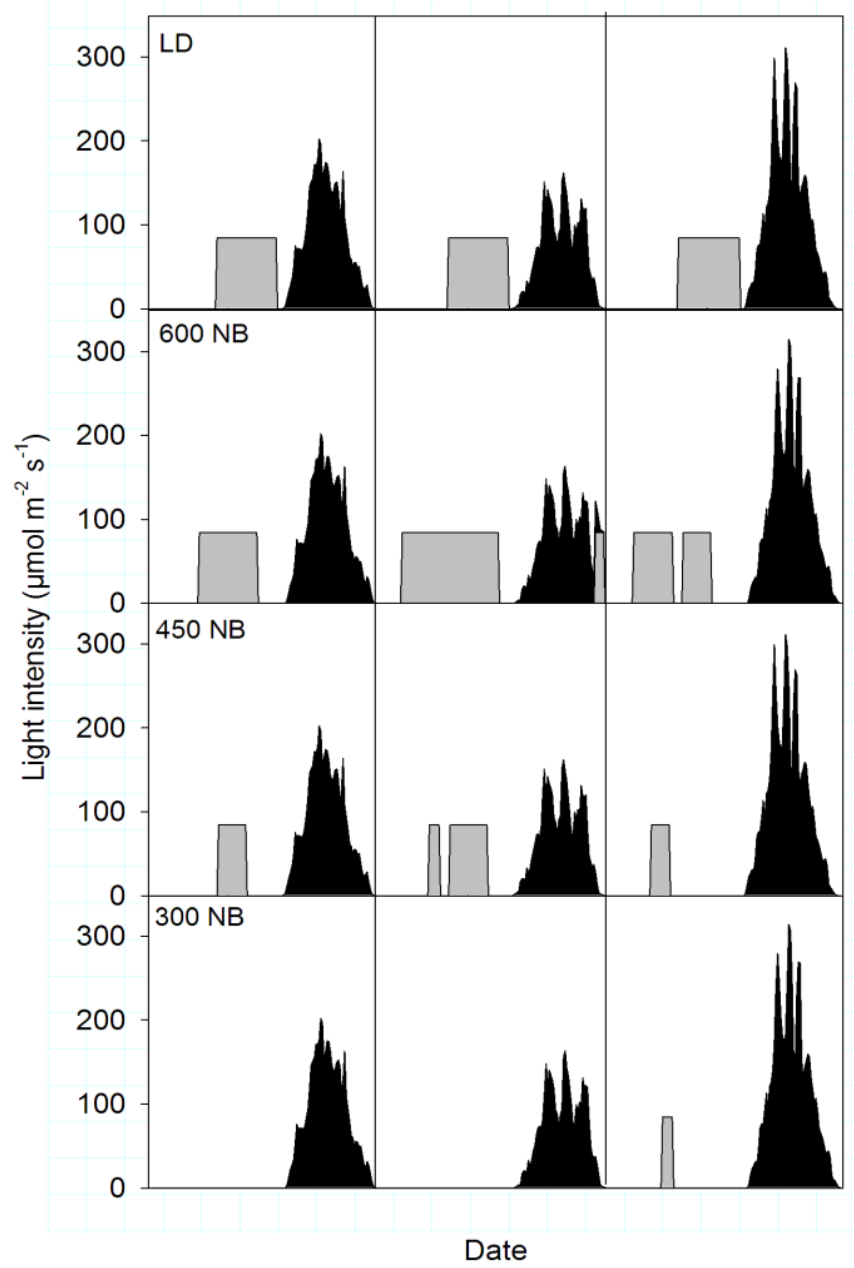

Figure 8. An example of daily light duration (DLD) and light intensities $\left(\mu \mathrm{mol} \mathrm{m} \mathrm{m}^{-2} \mathrm{~s}^{-1}\right.$ ) of solar irradiation (dark areas) and supplemental light (grey areas) in four greenhouse treatments with different light control strategies during three days in February 2010. Long day (LD) with a day length of $\sim 14 \mathrm{~h}, 600$ NB with a setpoint for daily photosynthesis integral (DPI) of $600 \mathrm{mmol} \mathrm{CO}_{2} \mathrm{~m}^{-2}$ leaf $d^{-1}, 450 \mathrm{NB}$ (DPI $\sim 450 \mathrm{mmol} \mathrm{CO}_{2} \mathrm{~m}^{-2}$ leaf $d^{-1}$ ) and $300 \mathrm{NB}$ (DPI $\sim 300 \mathrm{mmol} \mathrm{CO}_{2} \mathrm{~m}^{-2}$ leaf $d^{-1}$ ). NB refers to irregular night breaks of light.

An example of a light control scenario is illustrated in Figure9 (A) and (B) showing the results and light plans based on weather forecast and on measured values, respectively. We have calculated the result in Figure9 (A) to have an 8\% higher electricity cost and a 7\% excess of photosynthesis compared to Figure9 (B), which is the result of running the planning algorithm on the actual measured light conditions for the same day and aiming for equal DPI goals.

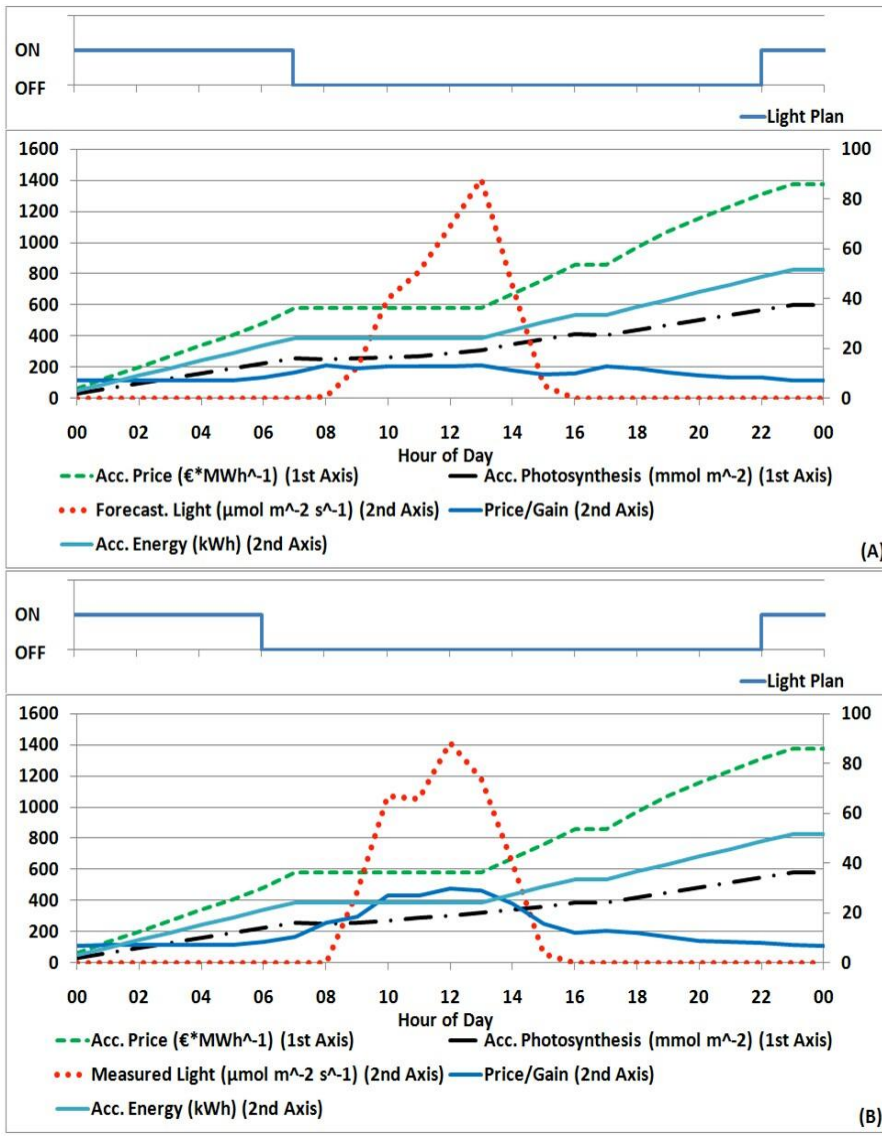

Figure 9. The resulting light plans created by the algorithm based on (A) forecasted solar irradiation and (B) based on measured solar irradiation.

\subsection{Energy Consumption and Electricity Costs}

Relative savings in electricity use and costs were obtained in the treatments $300 \mathrm{NB}$ in autumn and in $300 \mathrm{NB}$ and $450 \mathrm{NB}$ in spring in comparison to the LD treatment (Table 2) illustrating a potential to save up to $18 \%$ on energy use and costs by using dynamic light in comparison to a LD treatment of 14 hours. Important savings were also achieved in the 300 NB treatments, but in these treatments both plant growth and quality were reduced. In contrast, no additional flowers were formed using a DPI setpoint of $600 \mathrm{mmol} \mathrm{CO}_{2} \mathrm{~m}^{-2}$ leaf $\mathrm{d}^{-1}$, but the costs and use of electricity increased by $50 \%$.

Comparing the light plans from the LD treatment with the light plans used in the $300 \mathrm{NB}, 450 \mathrm{NB}$ and $600 \mathrm{NB}$ treatments it was found that between $14.23 \%$ and $19.29 \%$ of the light hours were moved in the $300 \mathrm{NB}$ treatment, between $7.8 \%$ and $10.63 \%$ of the light hours were moved in the $450 \mathrm{NB}$ treatment and between $3.15 \%$ and $3.33 \%$ of the light hours were moved in the $600 \mathrm{NB}$ treatment. These percentages show the amount of hours in which the lights were on in the LD treatment while they were turned off in the dynamic treatments. 
Table 1. Abiotic climate parameters and growth parameters for potted roses grown in four greenhouse treatments with different DynaLight control strategies ${ }^{b}$

\begin{tabular}{|c|c|c|c|c|c|c|c|}
\hline Experiment & Treatment & $\begin{array}{c}\text { DLI } \\
\left(\text { mol m}^{-2} d^{-1}\right)\end{array}$ & $\begin{array}{c}\text { DLD } \\
\left(h d^{-1}\right)\end{array}$ & $\begin{array}{c}\text { NB } \\
\left(h d^{-1}\right.\end{array}$ & $\begin{array}{c}\text { Light periods } \\
(\text { no. })\end{array}$ & $\begin{array}{c}\text { Plant DW } \\
(m g)\end{array}$ & $\begin{array}{c}\text { Flowers + buds } \\
(\text { buds no. })\end{array}$ \\
\hline Autumn 2009 & LD & $3.7 \pm 1.9 \mathrm{~b}^{\mathrm{c}}$ & $13.9 \pm 1.8 \mathrm{~b}$ & & & $5.5 \pm 1.1 \mathrm{c}$ & $5.0 \pm 1.8 \mathrm{a}$ \\
\hline & $600 \mathrm{NB}$ & $5.3 \pm 1.1 \mathrm{a}$ & $17.3 \pm 3.3 \mathrm{a}$ & $8.0 \pm 3.6 \mathrm{a}$ & $1.7 \pm 0.6$ & $8.1 \pm 1.1 \mathrm{a}$ & $5.4 \pm 1.3 \mathrm{a}$ \\
\hline & $450 \mathrm{NB}$ & $3.9 \pm 1.1 \mathrm{ab}$ & $14.2 \pm 3.2 \mathrm{~b}$ & $6.0 \pm 4.0 \mathrm{~b}$ & $2.0 \pm 0.7$ & $6.6 \pm 1.3 \mathrm{~b}$ & $5.5 \pm 2.4 \mathrm{a}$ \\
\hline & $300 \mathrm{NB}$ & $3.1 \pm 1.7 \mathrm{~b}$ & $10.8 \pm 2.2 \mathrm{c}$ & $2.7 \pm 2.9 \mathrm{c}$ & $1.6 \pm 0.7$ & $5.6 \pm 0.6 \mathrm{c}$ & $3.3 \pm 1.3 \mathrm{~b}$ \\
\hline Treatment x Cv. & & & & & & n.s. & n.s. \\
\hline Spring 2010 & LD & $3.9 \pm 1.1 \mathrm{~b}$ & $14.3 \pm 1.0 \mathrm{~b}$ & & & $8.9 \pm 2.4 \mathrm{~b}$ & $5.2 \pm 1.7 \mathrm{a}$ \\
\hline & $600 \mathrm{NB}$ & $5.2 \pm 1.3 \mathrm{a}$ & $17.6 \pm 3.0 \mathrm{a}$ & $8.9 \pm 2.3 \mathrm{a}$ & $1.9 \pm 0.5$ & $11.1 \pm 3.6 \mathrm{a}$ & $5.6 \pm 1.5 \mathrm{a}$ \\
\hline & $450 \mathrm{NB}$ & $3.9 \pm 0.8 \mathrm{~b}$ & $13.5 \pm 2.4 \mathrm{~b}$ & $5.04 \pm 2.4 \mathrm{~b}$ & $1.4 \pm 0.6$ & $7.8 \pm 2.0 \mathrm{bc}$ & $4.8 \pm 1.5 \mathrm{a}$ \\
\hline & $300 \mathrm{NB}$ & $2.6 \pm 1.0 \mathrm{c}$ & $9.6 \pm 1.3 \mathrm{c}$ & $1.3 \pm 1.5 \mathrm{c}$ & $1.8 \pm 0.6$ & $6.3 \pm 1.8 \mathrm{c}$ & $3.5 \pm 1.2 \mathrm{~b}$ \\
\hline Treatment x Cv. & & & & & & n.s. & n.s. \\
\hline
\end{tabular}

Table 2. Daily photosynthesis integral and cost of electricity for supplemental light in four greenhouse treatments with different light control strategies in autumn 2009 and spring $2010^{\mathrm{d}}$

\begin{tabular}{|c|c|c|c|c|c|}
\hline Experiment & Treatment & $\begin{array}{c}\text { DPI } \\
\left(\mathrm{mmol} \mathrm{CO}_{2} \mathrm{~m}^{-2} \text { leaf } \mathrm{d}^{-1}\right)\end{array}$ & $\begin{array}{c}\text { Electricity use } \\
\left(\mathrm{kWh} / \mathrm{m}^{2}\right)\end{array}$ & $\begin{array}{c}\text { Cost of electricity } \\
\left(\epsilon / \mathrm{m}^{2}\right)\end{array}$ & $\begin{array}{c}\text { Consumption/cost relative to LD treatment } \\
(\%)\end{array}$ \\
\hline Autumn 2009 & LD & 547.8 & 29.3 & 1.69 & $100 / 100$ \\
\hline & $600 \mathrm{NB}$ & 635.1 & 44.2 & 2.61 & $150 / 154$ \\
\hline & $450 \mathrm{NB}$ & 494.1 & 31.8 & 1.83 & $108 / 108$ \\
\hline & $300 \mathrm{NB}$ & 320.2 & 12.42 & 0.7 & $100 / 41$ \\
\hline Spring 2010 & LD & 455.3 & 31.4 & 1.78 & $151 / 157$ \\
\hline & $600 \mathrm{NB}$ & 589.5 & 47.4 & 2.8 & $84 / 82$ \\
\hline & $450 \mathrm{NB}$ & 401.5 & 26.4 & 1.46 & $28 / 25$ \\
\hline & $300 \mathrm{NB}$ & 249.5 & 8.9 & 0.45 & \\
\hline
\end{tabular}

${ }^{\mathrm{b}}$ Treatments were long day (LD) with a day length of $\approx 14 \mathrm{~h}, 600 \mathrm{NB}$ with a set point for daily photosynthesis integral (DPI) of $600 \mathrm{mmol} \mathrm{CO}_{2} \mathrm{~m}^{-2}$ leaf $\mathrm{d}^{-1}, 450 \mathrm{NB}\left(\mathrm{DPI} \approx 450 \mathrm{mmol} \mathrm{CO}_{2} \mathrm{~m}^{-2}\right.$ leaf $\mathrm{d}^{-1}$ ) and 300NB (DPI $\approx 300 \mathrm{mmol} \mathrm{CO}_{2} \mathrm{~m}^{-2}$ leaf $\mathrm{d}^{-1}$ ). Values are average values for daily light integral (DLI), daily light duration (DLD), length of night breaks of light (NB) and number of light periods. For growth parameters average values are given for plants' dry weight and the number of flowers + buds for each treatment $( \pm \mathrm{SE})$. The three varieties of roses were pooled $(n=24)$

${ }^{c}$ Different letters indicate significant differences in probability values between treatments within each experiment $(P<0.05)$.

${ }^{\mathrm{d}}$ Treatments were long day (LD) with a day length of $\approx 14 \mathrm{~h}, 600 \mathrm{NB}$ with a set point for daily photosynthesis integral (DPI) of $600 \mathrm{mmol} \mathrm{CO}_{2} \mathrm{~m}^{-2}$ leaf $\mathrm{d}^{-1}, 450 \mathrm{NB}$ (DPI $\approx 450 \mathrm{mmol} \mathrm{CO}_{2} \mathrm{~m}^{-2}$ leaf $\mathrm{d}^{-1}$ ) and $300 \mathrm{NB}$ (DPI $\approx 300 \mathrm{mmol} \mathrm{CO}_{2} \mathrm{~m}^{-2}$ leaf $\mathrm{d}^{-1}$ ). The DPI is the mean, and electricity use and cost of electricity are the sum for two months in autumn 2009 (1 Oct. - 29 Nov.) and two months in spring 2010 (1 Jan. - 27 Feb.) and calculated on the basis of the price of electricity during the relevant hours that the supplemental light was turned on.

\section{DISCUSSION}

By integrating the supplemental light control of a greenhouse climate control system with weather forecasts, electricity prices, and photosynthetic responses of ornamental plants, greenhouses were found to be able to participate in an RTP DR program without noticeable reductions in plant growth and development for pot roses. Further, a reduction in the net electricity costs can be achieved. This result is supported by earlier results on chrysanthemum and campanula species (Kjær, et al., 2011) (Kjær \& Ottosen, 2011).

In the spring pot-rose experiment, we obtained a dynamic light treatment where the quality of the plants was equal to the LD plants but with an $18 \%$ reduction in electricity costs and use as well as an ability to act according to the intentions of the RTP DR program. The saving achieved was comparable to results in campanula (Kjær, et al., 2011) and illustrates clearly that savings on energy and electricity in the range of $18-25 \%$ is realistic without any significant reductions in plant quality. In the present experiment it was further illustrated that increased use of supplemental light in comparison to the light used in LD does not necessarily result in a better product quality as the number of flowers and buds in the $600 \mathrm{NB}$ and $450 \mathrm{NB}$ was similar to plants grown in LD. However, it is important to note that although the autumn experiments for plants grown in the $300 \mathrm{NB}$ dynamic light treatment did result in plants of similar size and production time as plants 
grown in an LD treatment at a significant energy cost-efficiency optimization of $60 \%$, it caused a reduction in the number of flowers and buds compared to the LD. This illustrates the trade-off between light requirements for optimized plant quality in relation to the cost of supplemental light. It also shows that the developed software is a powerful tool for understanding and designing the optimal supplementary light conditions for plant production with the lowest energy cost.

So far we have conducted several experiments using dynamic light to determine different ornamental plant species' responses to cost-efficient supplemental light control and it is obvious that it is possible to achieve substantial savings if the use of supplemental light is allowed to fluctuate according to the hourly electricity price. However, there still remain a number of questions regarding how species with different photoperiodic requirements will respond when subjected to irregular light periods. Also, there are questions about why some plants seem to have increased dry-matter production, when they are grown in irregular light conditions with similar DLI as in LD conditions (Kjær, et al., 2011), and questions about why effects of irregular light on diurnal processes regulated by the circadian clock do not seem to have major impact on the overall plant growth and development (Dodd, et al., 2005) (Resco, et al., 2009) (Kjær \& Ottosen, 2011). Furthermore, in the experiments we maintained the same target for DLI throughout the experiments. However, the differences in responses to light in periods with increasing natural light vs. decreasing light need further exploration.

The software's ability to create light plans, which fulfill the DPI goals, depends on the precision of the weather forecasts, i.e. the predicted solar irradiation. We have observed discrepancies between light plans created based on the weather forecasts and based on the actual weather conditions because the weather forecasts deviate from the actual measurements. It is outside the scope of this research and our area of expertise to work on weather models, but we will discuss how different scenarios might influence the resulting energy consumption and electricity costs. Two main scenarios could be proposed: 1) the measured solar irradiation is higher than predicted 2) the measured solar irradiation is lower than predicted. The first scenario can result in superfluous supplemental light being turned on, and if that is the case, the resulting DPI will overshoot the DPI goal and the superfluous electricity consumed will lead to unnecessary expenses. The second scenario can lead to less than needed supplemental light. This behavior can cause reduced production quality, similar to what we saw in the pot-rose treatment $300 \mathrm{NB}$ in spring. However, it would of course lead to larger energy and electricity-cost savings, which was also shown for the same treatment. The effect of the weather forecast accuracy on the DPIs, energy consumption and electricity costs of the light plans created by DynaLight Desktop over a long period of time is part of our future research.

There are several ways to minimize the effects of the discrepancies between the forecasted light levels and the actual light levels. One way is to adjust the light plan by using light sensors inside the greenhouse, thereby continuously adapt the plan to the actual conditions. It is part of our future research to evaluate the effect of this kind of improvement, as well as other improvements and refinements to the algorithm. However, the scope of this interdisciplinary project has been to validate the coarse-grained effects on the electricity price, quality and energy consumption of plant production by utilizing the combined information on electricity prices, photosynthesis models, plasticity in reaction to light and weather forecasts.

A lesson learned from this experiment is that human factors also need to be considered. One of the reasons for only creating light plans statically once a day is that growers want to be able to inspect the plans, and to be able to intervene in case the plans do not adhere to their criteria. In our case the move towards real-time autonomous computer-controlled supplementary light plan creation needs to be done in small steps so the confidence in the systems steadily builds up.

With our experiments we have shown, that greenhouses are indeed capable of participating in a DR program. This is supported by the results of our $450 \mathrm{NB}$ and $600 \mathrm{NB}$ treatments, in which the quality of the flowers did not diminish compared to the traditional LD treatment. Further we found that using the $450 \mathrm{NB}$ treatment, the growers were able to move between $7.80 \%$ to $10.63 \%$ of their total light hours compared to the LD treatment. This illustrates an important point, since this represent a generic flexibility; the grower had two choices (3 counting the $600 \mathrm{NB}$ treatment) which accomplished the same quality of plants. We envision that this generic flexibility may be utilized both to reduce electricity peak consumption and to ease the integration of fluctuating energy sources to the power grid. As roughly $198 \mathrm{GWh}$ of the $265 \mathrm{GWh}$ of electricity consumed by the Danish growers are used for supplemental lightning, this means that potentially Danish growers are able to move $21 \mathrm{GWh}$ of electricity consumption, or $0.06 \%$ of the total Danish electricity consumption out of peak consumption periods.

Having supported the claim that greenhouses may indeed be well integrated in a DR program, we are encouraged to continue our research to create a framework in which enables growers to seamlessly engage in various DR programs, while being capable of maintaining production quality. 


\section{CONCLUSION}

We have shown the ability to successfully engage protected cultivation into a RTP DR program. The software developed was able to generate cost efficient supplemental light schedules, which makes it possible to obtain a significant reduction in the cost of energy consumption by utilizing weather forecasts and the hourly electricity prices for the forthcoming day.

The decrease in energy cost was achieved without noticeable effect on the plant quality in the spring, and since the temperatures were maintained identical in the experiment, the production time was not affected, while the number of flowers decreased slightly depending of time of year and plant species and cultivar.

Enabling consumers to participate in demand response programs becomes crucial in the coming years and with DynaLight Desktop application, we have shown that growers may seamlessly engage their production into RTP DR programs, ensuring an improved climate control with fewer costs for an optimized plant production.

Our experiments showed that we were able to reallocate between $7.8 \%$ and $10.6 \%$ of the light hours used for supplemental lightning with respect to the standard day-lengthening light scheme. This corresponds to Danish growers being able to move $21 \mathrm{GWh}$ of electricity consumption, which could potentially contribute significantly to the reduction of peak consumption in Denmark.

\section{REFERENCES}

[1] Albadi, M. H., \& El-Saadany, E. F. (2008). A summary of demand response in electricity markets. Electric Power Systems Research, pp. 1989-1996.

[2] Barker, S., Mishra, A., Irwin, D., Shenoy, P., \& Albrecht, J. (2012). Smartcap: Flattening peak electricity demand in smart homes. Pervasive Computing and Communications (PerCom), 2012 IEEE International Conference on, pp. 67-75.

[3] Cappers, P., Mills, A., Goldman, C., Wiser, R., \& Eto, J. H. (2012). An assessment of the role mass market demand response could play in contributing to the management of variable generation integration issues. Energy Policy, pp. 420-429.

[4] Currey, C. J., \& Erwin, J. E. (2010). Variation among Kalanchoe species in their flowering responses to photoperiod and short-day cycle number. Journal of Horticultural Science and Biotechnology, pp. 350-354.

[5] Dam, Q. B., Mohagheghi, S., \& Stoupis, J. (2008). Intelligent demand response scheme for customer side load management. Energy 2030 Conference, 2008. ENERGY 2008. IEEE, pp. 1-7.

[6] Dansk Gartneri. (2011). Retrieved July 24th, 2014, from http://www.danskgartneri.dk/Nyheder/Nyhedsarkiv/2011/ Marts/Nye_store_energibesparelser_i_vaeksthusgartnerier ne.aspx

[7] Dodd, A. N., Salathia, N., Hall, A., Kévei, E., Tóth, R., Nagy, F., . . . Webb, A. A. (2005). Plant circadian clocks increase photosynthesis, growth, survival, and competitive advantage. Science Signaling, pp. 630-633.

[8] Gauthier, L., \& Guay, R. (1990). An object-oriented design for a greenhouse climate control system. Transactions of the ASAE, pp. 999-1004.

[9] Han, J., \& Piette, M. A. (2008). Solutions for Summer Electric Power Shortages: Demand Response and Its Application in Air Conditioning and Refrigerating Systems. Refrigeration, Air Conditioning, \& Electric Power Machinery, pp. 1-4.

[10] Hansen, J., \& Høgh-Schmidt, K. (1996). A computer controlled chamber system designed for greenhouse microclimatic modelling and control. International Symposium on Plant Production in Closed Ecosystems 440, pp. 310-315.

[11] Hesser, T., \& Succar, S. (2011). Renewables Integration Through Direct Load Control and Demand Response. Smart Grid, pp. 209-233.

[12] Jones, H. G. (1998). Stomatal control of photosynthesis and transpiration. Journal of Experimental Botany, pp. 387-398

[13] Karlsson, M. G., \& Werner, J. W. (2002). Flowering of Primula malacoides in response to photoperiod and temperature. Scientia Horticulturae, pp. 351-356.

[14] Kjær, K. H., \& Ottosen, C.-O. (2011). Growth of chrysanthemum in response to supplemental light provided by irregular light breaks during the night. Journal of the American Society for Horticultural Science, pp. 3-9.

[15] Kjær, K. H., Ottosen, C.-O., \& Jørgensen, B. N. (2011). Cost-efficient light control for production of two campanula species. Scientia Horticulturae, pp. 825-831.

[16] Kjær, K. H., Ottosen, C.-O., \& Jørgensen, B. N. (2012). Timing growth and development of Campanula by daily light integral and supplemental light level in a costefficient light control system. Scientia Horticulturae, pp. 189-196.

[17] Körner, O. (2003). Crop based climate regimes for energy saving in greenhouse cultivation.

[18] Langton, F. A., Adams, S. R., \& Cockshull, K. E. (2003). Effects of photoperiod on leaf greenness of four bedding plant species. Journal of horticultural science \& biotechnology, pp. 400-404.

[19] Liu, B., \& Heins, R. D. (2002). Photothermal Ratio Affects Plant Quality in 'Freedom' Poinsettia. Journal of the American Society for Horticultural Science, pp. 2026.

[20] Markvart, J., Rosenqvist, E., Sørensen, H., Ottosen, C.-O., \& Aaslyng, J. M. (2009). Canopy photosynthesis and time-of-day application of supplemental light. Journal of the American Society for Horticultural Science, pp. 12841290.

[21] Mattson, N. S., \& Erwin, J. E. (2005). The impact of photoperiod and irradiance on flowering of several herbaceous ornamentals. Scientia Horticulturae, pp. 275292.

[22] Moccaldi, L. A., \& Runkle, E. S. (2007). Modeling the Effects of Temperature and Photosynthetic Daily Light Integral on Growth and Flowering of Salvia splendens and Tagetes patula. Journal of the American Society for Horticultural Science, pp. 283-288.

[23] Motegi, N., Piette, M. A., Watson, D. S., Kiliccote, S., \& $\mathrm{Xu}$, P. (2007). Introduction to commercial building control strategies and techniques for demand response. Lawrence Berkeley National Laboratory, Berkeley.

[24] Oh, W., Cheon, I. H., Kim, K. S., \& Runkle, E. S. (2009). Photosynthetic daily light integral influences flowering time and crop characteristics of Cyclamen persicum. 
Journal of the American Society for Horticultural Science, pp. 341-344.

[25] Palensky, P., \& Dietrich, D. (2011). Demand side management: Demand response, intelligent energy systems, and smart loads. Industrial Informatics, IEEE Transactions on, pp. 381-388.

[26] Piette, M. A., Watson, D., Motegi, N., Kiliccote, S., \& $\mathrm{Xu}, \mathrm{P}$. (2006). Automated Critical Peak Pricing field tests: Program description and results.

[27] Resco, V., Hartwell, J., \& Hall, A. (2009). Ecological implications of plants' ability to tell the time. Ecology letters, pp. 583-592.

[28] Rohwer, C. L., \& Heins, R. D. (2007). Daily Light Integral, Prevernalization Photoperiod, and Vernalization Temperature and Duration Control Flowering of Easter Cactus. Journal of the American Society for Horticultural Science, pp. 1596-1604.

[29] Runkle, E. S., Heins, R. D., Cameron, A. C., \& Carlson, W. H. (1998). Flowering of herbaceous perennials under various night interruption and cyclic lighting treatments.
Journal of the American Society for Horticultural Science, pp. 672-677.

[30] Samad, T., \& Kiliccote, S. (2012). Smart grid technologies and applications for the industrial sector. Computers \& Chemical Engineering.

[31] Seki, H., Kurimoto, M., \& Sugaya, H. (2005). Basic Experiment on the Environment in a Miniature Sloped Greenhouse with Model Plants. Journal of agricultural meteorology - Tokyo.

[32] Thomas, B., \& Vince-Prue, D. (1996). Photoperiodism in plants. Academic Press.

[33] Aalami, H., Yousefi, G. R., \& Moghadam, M. P. (2008). Demand response model considering EDRP and TOU programs. Transmission and Distribution Conference and Exposition, 2008. T\&D. IEEE/PES, pp. 1-6.

[34] Aaslyng, J. M., Lund, J., Ehler, N., \& Rosenqvist, E. (2003). IntelliGrow: a greenhouse component-based climate control system. Environmental Modelling \& Software, pp. 657-666. 